\title{
Análise e projeto de estrutura de contenção em ruptura de talude por erosão: estudo de caso
}

Os processos erosivos fundamentam-se essencialmente na desagregação, transporte e deposição do solo, com a ação dos agentes erosivos água, ventos e ou gelo. Sabe-se que o solo tem uma capacidade de suportar esforços, porém, se suas características forem alteradas, a capacidade de carga sofrerá alterações, podendo torna-se um solo frágil, um fator com a característica de diminuir a resistência do solo é a erosão. Diante do exposto o artigo propõe analisar e dimensionar uma estrutura de gabião para conter o processo erosivo do solo situado no município de Porto Nacional, nas proximidades do ribeirão São João, na Av. Padre Luso. Destaca-se que esta ruptura está à menos de um metro de distância de uma edificação e caso persista irá atingir mais cinco edificações circunvizinhas. Neste estudo foram realizados ensaios de caracterização do solo. Na análise de estabilidade da estrutura de gabião proposta para contenção do talude, foram verificados os critérios de deslizamento, tombamento e capacidade de carga conforme a NBR 11682/1991. Além disso, também foi feita a análise global do sistema talude/muro. Verificou-se que a estrutura proposta atende os requisitos técnicos de segurança.

Palavras-chave: Erosão; Estruturas de Contenção; Estabilidade de taludes.

\section{Analysis and design of containment structure in eruption talud rupture: case study}

\begin{abstract}
The erosive processes are essentially based on the disintegration, transport and deposition of the soil, with the action of erosive agent's water, winds and or ice. It is known that the soil has a capacity to withstand stresses, however, if its characteristics are altered, the load capacity will undergo changes, being able to become a fragile soil, a factor with the characteristic of diminishing soil resistance is erosion. In view of the above, the article proposes to analyze and size a gabion structure to contain the soil erosion process located in the municipality of Porto Nacional, in the vicinity of the São João stream, on Padre Luso Avenue. It should be noted that this rupture is less than one meter away from a building and if it persists it will reach another five surrounding buildings. In this study, soil characterization tests were carried out. In the stability analysis of the gabion structure proposed for containment of the slope, the sliding, tipping and load capacity criteria were verified according to NBR 11682/1991. In addition, the overall analysis of the slope / wall system was also performed. It was found that the proposed structure meets the technical safety requirements.
\end{abstract}

Keywords: Erosion; Containment Structures; Stability of slopes.

\section{Topic: Engenharia Civil}

Reviewed anonymously in the process of blind peer.
Received:14/06/2018

Approved: 24/09/2018
Laylla Ribeiro da Silva

Faculdade Presidente Antônio Carlos, Brasil

layllaeng@hotmail.com

\section{Talita Caroline Miranda}

Faculdade Presidente Antônio Carlos, Brasil

http://lattes.cnpq.br/7173437103345457

talitamiranda@itpacporto.com.br
Referencing this:

SILVA, L. R.; MIRANDA, T. C.. Análise e projeto de estrutura de contenção em ruptura de talude por erosão: estudo de caso. Engineering Sciences, v.6, n.2, p.12-22, 2018. DOI: http://doi.org/10.6008/CBPC2318-3055.2018.002.0002

DOI: 10.6008/CBPC2318-3055.2018.002.0002 


\section{INTRODUÇÃO}

Erosão é um termo associado com o processo de desgaste da superfície terrestre em solo ou rocha, pela ação do vento, da água, do gelo, de organismos vivos, plantas e animais, e pela ação antrópica. 0 processo erosivo pode ser classificado quanto à sua origem em dois grandes grupos: erosão geológica ou natural e erosão acelerada ou antrópica (CAMAPUM et al., 2006).

As principais erosões que são estudadas no meio geotécnico são de origem hídrica: Estas são chamadas de erosões lineares e são classificadas conforme o aparecimento de água, pois com o não surgimento denomina-se ravina e com a sua surgência voçoroca. Os agentes externos que atuam nos processos erosivos são: condições de percolação, potencial de erosividade fluvial, escoamento superficial e a sua inclinação do terreno, além desses agentes ainda se inclui os agentes internos como o gradiente crítico, erodibilidade do solo e a desagregabilidade (GUERRA, 2005).

Com o crescimento das cidades continuamente acelerado as atividades humanas não planejadas como a ocupação inadequada de solos e a falta de drenagem urbana adequada têm acelerado intensamente estes fenômenos, surgindo zonas de risco ambiental e um número cada vez maior de acidentes geológicos, modificando o comportamento hidrológico do solo, favorecendo a instabilidade e seu deslizamento.

Em áreas urbanas o controle dos processos erosivos é algo corriqueiro, muitas vezes, a forma de se projetar as obras de drenagem acaba trazendo lacuna, em que seus métodos variam de acordo com sua região. Cada particularidade terá uma atenção especial devido às soluções individuais ou grandes projetos como manutenção de área permeáveis dentro dos lotes executar estruturas de micro e macrodrenagem (DOMINGUES et al., 1998).

Dessa maneira este trabalho tem objetivo de caracterizar os solos presentes em uma ruptura de taludes causada por erosão hídrica, situada na cidade de Porto Nacional. Além disso, o trabalho propõe o projeto geotécnico de uma estrutura de contenção. O local de estudo escolhido para este trabalho se deu, pois, a erosão causada por uma drenagem urbana deficiente que está colocando em risco moradias e vidas humanas. Por fim será entregue para estas famílias uma solução de recuperação da área com fins de estabilidade dos taludes de entorno, conforme descrito a seguir. A primeira etapa, após a escolha do local, foi à análise da problemática nas proximidades do Ribeirão São João, na Av. Padre Luso, centro, município de Porto Nacional (FIG. 2), para identificar os tipos de solos e caracterizá-los.

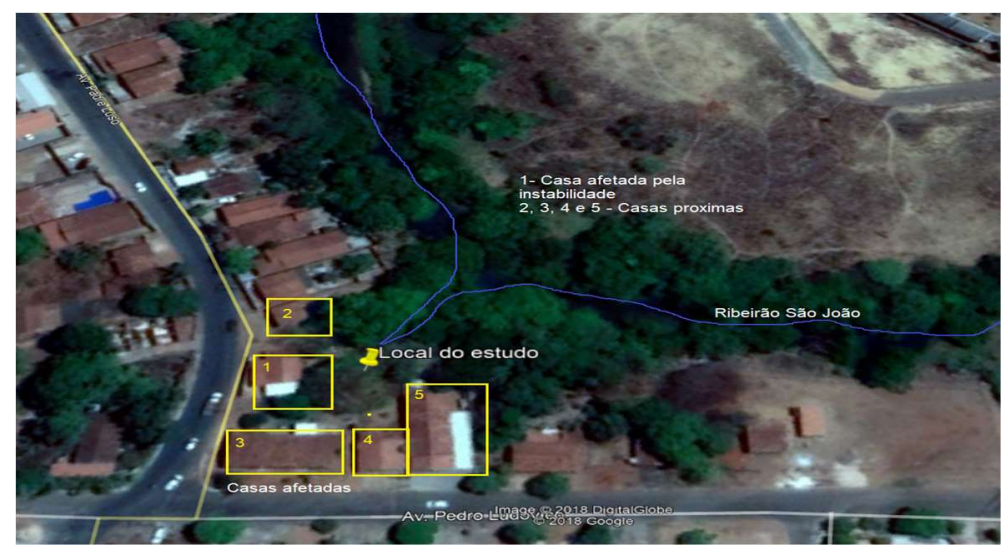

Figura 1: Localização da área de estudo. 


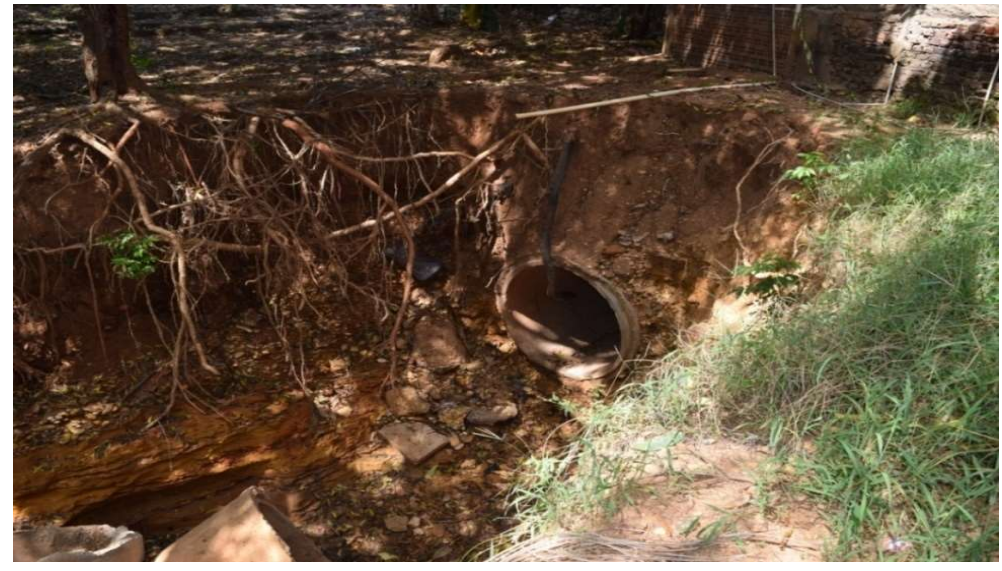

Figura 2: Erosão - Local do estudo.

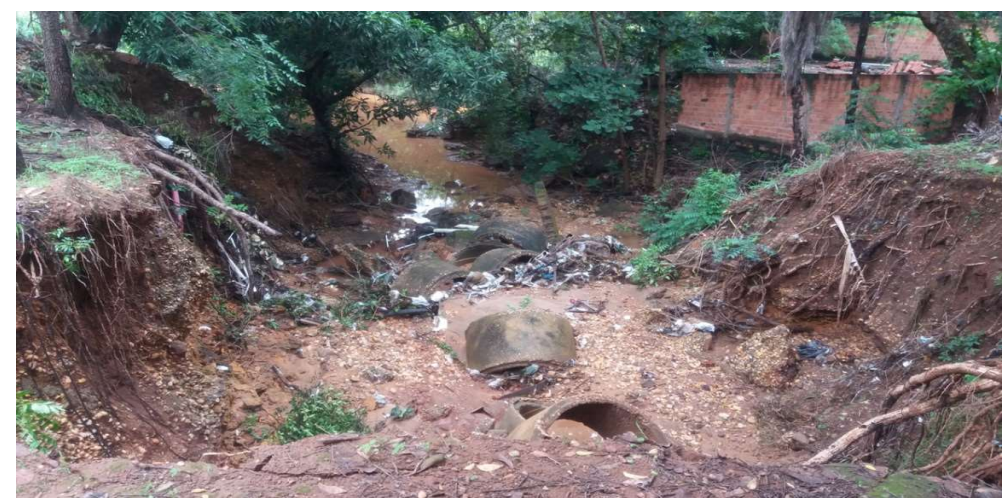

Figura 3: Erosão - Local do estudo.

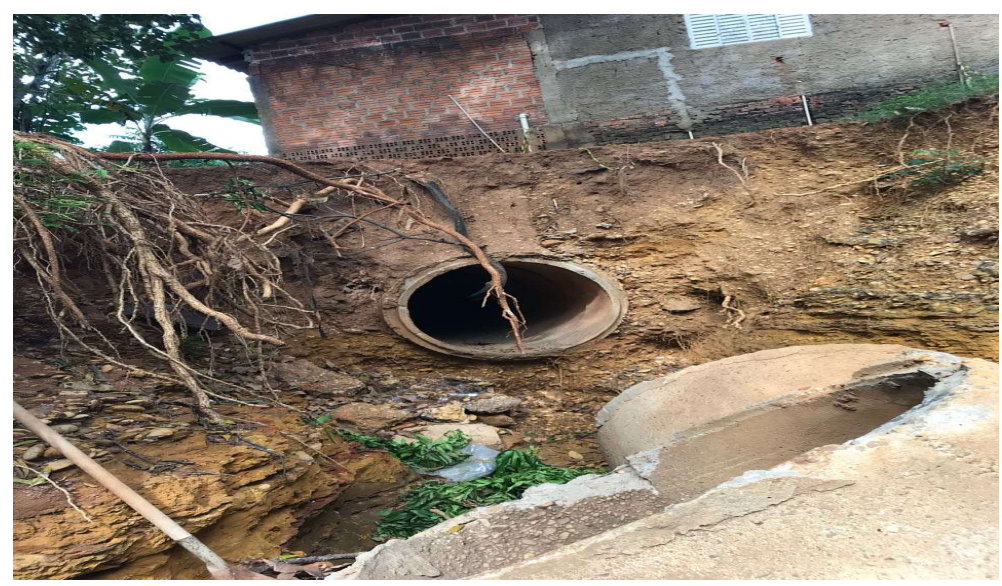

Figura 4: Erosão - Local do estudo.

\section{REVISÃO TÉORICA}

\section{Análise de estabilidade}

Os métodos de análise de estabilidade de taludes são divididos em duas categorias: métodos determinísticos, nos quais a medida da segurança do talude é feita em termos de um fator de segurança e métodos probabilísticos, nos quais a medida de segurança é feita em termos da probabilidade ou do risco de ocorrência da ruptura. Neste trabalho optou-se por utilizar o método de análise de estabilidade, por ser o mais utilizado e por permitir o projeto de uma estrutura de contenção.

$\mathrm{Na}$ análise de estabilidade de um muro de arrimo, seja qual for a sua seção, devem ser investigadas as seguintes condições de estabilidade: tombamento, deslizamento da base, capacidade de carga da 
fundação e ruptura global. O dimensionamento inicia-se com um pré-dimensionamento sugestivo estabelecido. Em seguida, é feita a verificação de estabilidade do muro de arrimo para comprovar se as dimensões adotadas são aceitáveis e oferecem segurança à estrutura (GERSCOVICH, 2008).

De acordo com Carmo (2009), os taludes podem ter sua estabilidade abalada por sua forma e inclinação das encostas, chuvas, natureza da cobertura vegetal, dispositivos de drenagem mal dimensionados e/ou comprometidos, características e estado dos solos (ou rochas), natureza geológica (litológica e estrutural) do meio, tensões internas, abalos naturais e induzidos e ação antrópica de ocupação.

Conforme Barbosa (2008), um talude pode ser considerado como potencialmente instável a partir do momento em que as tensões tangenciais originadas por esforços desestabilizadores são ou possam tornar-se maiores que a resistência ao corte do material que constitua a zona do maciço que permita definir uma região potencial de ruptura. Assim, os fatores que, por um lado, aumentam ou introduzem tensões de corte ou por outro, que diminuem a resistência ao corte do maciço são os responsáveis pelas condições gerais que favorecem a desestabilização de taludes.

\section{Estrutura de contenção - muro de gabião}

Estruturas de contenção - também chamadas de estruturas de arrimo - são aquelas que têm por finalidade estabilizar maciços de rocha ou terra, dando suporte a estes contra a ruptura e evitando assim seu escorregamento, o qual pode ser causado pelo peso próprio ou por carregamentos externos (MACCAFERRI, 2010).

Muros de gabiões são muros de gravidade constituídos por elementos metálicos confeccionados com telas de malha hexagonal de dupla torção de arame galvanizado preenchidos por pedras (MACCAFERRI, 2009). As pedras devem possuir granulometria adequada, ou seja, diâmetros que sejam no mínimo superiores à abertura da malha das gaiolas. Os gabiões são elementos modulares que podem ser costurados uns aos outros, podendo admitir formas prismáticas ou cilíndricas. Esse tipo de muro de gravidade é muito utilizado em canais e cursos d'água, atuando na contenção das margens.

As características geotécnicas dos gabiões usualmente adotadas para o caso de rocha granito em projeto são: peso específico $=17 \mathrm{kN} / \mathrm{m} 3$ e ângulo de atrito $=35$ ㅇ․ As principais vantagens são: custo reduzido, especialmente quando os blocos de pedras são disponíveis no local; flexibilidade elevada, permitindo deformações diferenciais do retroaterro e do terreno de fundação do muro; resistência elevada, devida ao peso dos gabiões e ao coeficiente de atrito dos blocos de rocha sã; e permeabilidade elevada, devida à granulometria uniforme dos blocos, que garante a drenagem da encosta e a ausência de empuxo no tardoz do muro. São de grande agilidade na construção e adaptam-se bem com a vegetação local (PEREIRA, 1996).

As principais desvantagens desse sistema de contenção são: limitação da altura; considerável consume de material; necessidade de muito espaço e possui peso elevado podendo causar possíveis problemas de capacidade de carga e recalque. Para alturas superiores a mais ou menos 4 metros, o muro de gabiões se torna uma solução antieconômica. 
Para analisar a estabilidade do muro em questão, foi realizado, primeiramente, um prédimensionamento, avaliando os aspectos do talude e os valores usuais de dimensões de muros de gabião, através do Manual da Maccaferri (2009). As dimensões dos gabiões caixa são padronizadas: Comprimento, sempre múltiplo de $1 \mathrm{~m}$, varia de $1 \mathrm{~m}$ a $4 \mathrm{~m}$, com exceção do gabião de 1,5 m; Largura é sempre de $1 \mathrm{~m}$; Altura pode ser de $0,50 \mathrm{~m}$ ou $1,00 \mathrm{~m}$.

\section{METODOLOGIA}

Para a resolução da problemática descrita foram adotados os passos representados na figura a seguir. O problema avaliado neste trabalho é de uma erosão causada por a ruptura de tubulação de drenagem pluvial que ocorreu no município de Porto Nacional, descrito anteriormente. Conforme o relato da moradora afetada, a solução recorrente aplicada pelo poder público é a reconstrução da tubulação de drenagem. Após algumas chuvas intensas, no período de chuva, a ruptura volta a ocorrer. Por ser um problema recorrente foi proposta uma estrutura de contenção permanente do tipo muro de contenção por gravidade, no caso o uso de gabião. Na figura 6 é apresentado as dimensões adotadas para o muro de gabião.

Para o dimensionamento do muro de gabião foram adotadas dimensões descritas, a fim de otimizar e permitir uma maior viabilidade construtiva, econômica e técnica. Posteriormente a partir dos parâmetros obtidos em ensaios laboratoriais, fizeram-se verificações para cada uma das condições de estabilidade. Para a definição dos parâmetros do projeto a serem adotados nas estruturas de contenção foram coletadas amostras de solo (deformado e indeformado) e definidos os ensaios de laboratório que foram realizados. No Quadro 1 apresenta as características dos ensaios realizados.

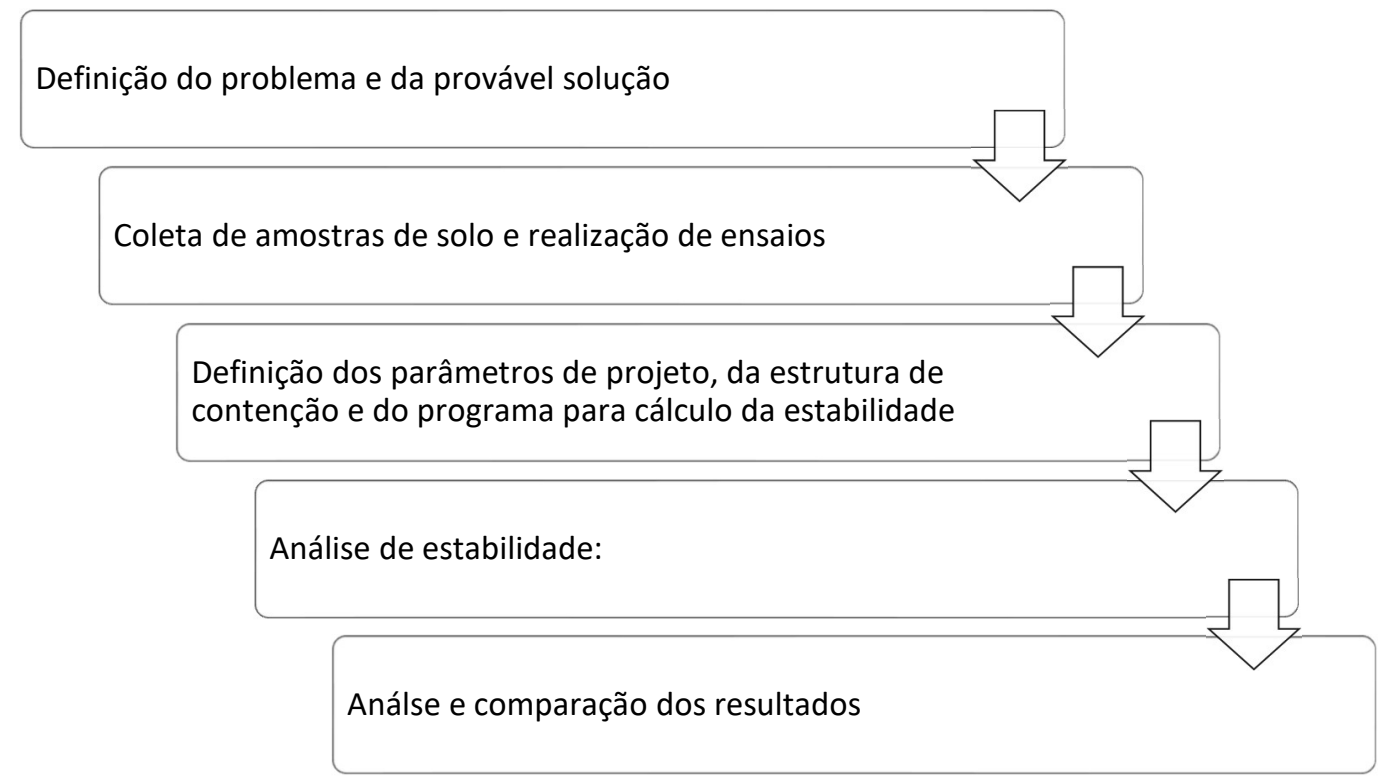

Figura 5: Fluxo metodológico. 


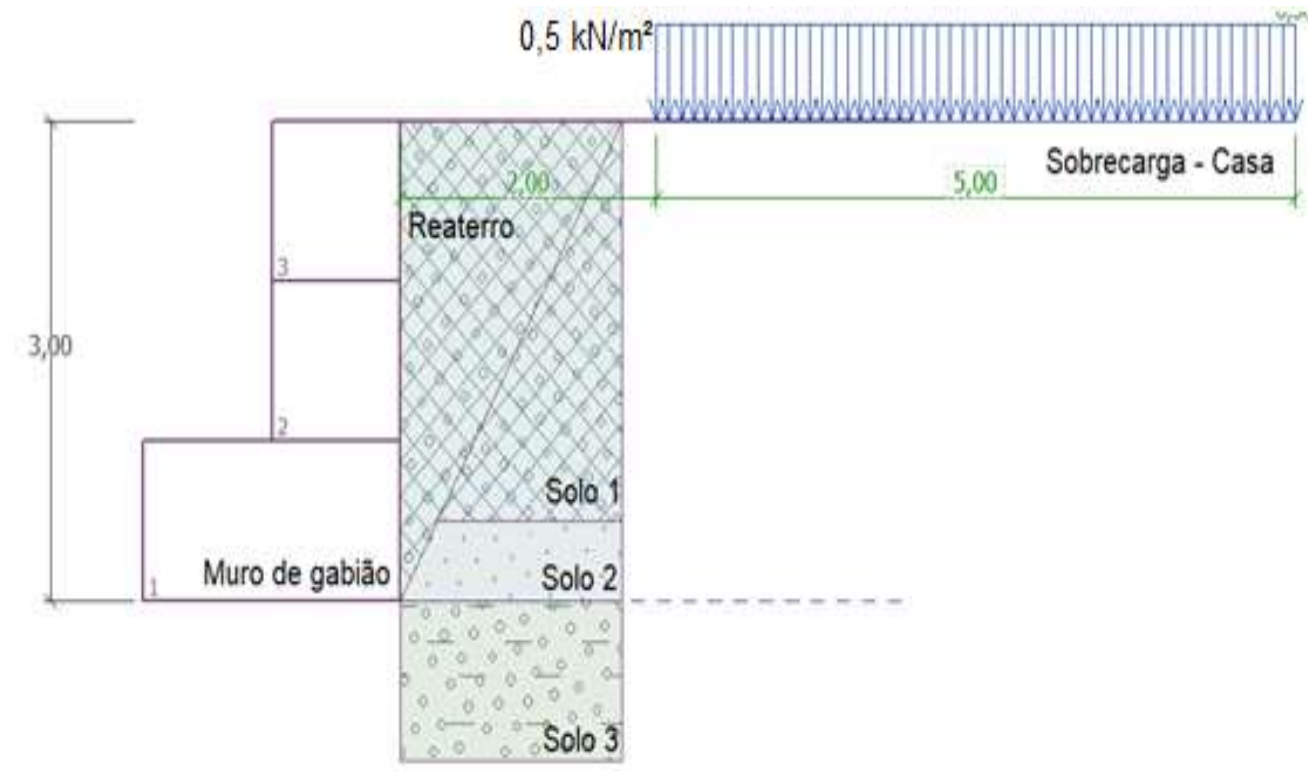

Figura 6: Dimensões adotadas do muro de gabião.

Obtido os parâmetros do solo, foi escolhido o Sistema GEO5 para auxiliar o dimensionamento e verificação da estabilidade do muro. O sistema é um conjunto de programas para a análise geotécnica, que inclui aplicativos individuais utilizados para a solução de problemas geotécnicos específicos. Cada programa permite a análise da estrutura de acordo com os aspectos geotécnicos e também verifica o material do muro, dispondo no manual do programa.

Nesta análise foi utilizada o módulo do programa chamado Muro de Gabião. Neste o programa analisa qualquer forma de muro, incluindo estruturas com saliências que necessitam ancoragens. 0 programa permite a verificação complexa da estrutura analisada pelo método clássico (estados limite, fator de segurança), além de permitir a verificação da capacidade de carga e da estimativa de recalque na base do muro. Também inclui o módulo para a verificação da estabilidade global do conjunto muro e talude. Os métodos de análise e hipóteses adotadas estão descritos a seguir.

Quadro 1: Ensaios Caracterização geotécnica.

\begin{tabular}{|c|c|c|}
\hline Ensaio & Norma & Características \\
\hline $\begin{array}{l}\text { Preparaçã } \\
\text { o das } \\
\text { amostras }\end{array}$ & $\begin{array}{l}\text { (NBR 6457/69) - Preparação de amostras de } \\
\text { solo para ensaio normal de compactação e } \\
\text { ensaios de caracterização. }\end{array}$ & $\begin{array}{l}\text { Tem como intuito de preparar as amostras para se ter a umidade } \\
\text { higroscópica. }\end{array}$ \\
\hline $\begin{array}{l}\text { Granulom } \\
\text { etria }\end{array}$ & $\begin{array}{l}\text { (NBR 7181/84) - Solo - Análise } \\
\text { granulométrica }\end{array}$ & $\begin{array}{l}\text { Objetiva mostrar as frações representadas do solo em porcentagem } \\
\text { de peso no ensaio, através de uma curva granulométrica em escala } \\
\text { logarítmica. }\end{array}$ \\
\hline $\begin{array}{l}\text { Massa } \\
\text { específica } \\
\text { dos sólidos }\end{array}$ & $\begin{array}{l}\text { (NBR } 6508 / 84 \text { ) - Grãos de solo que passa na } \\
\text { peneira de } 4,8 \mathrm{~mm} \text {. }\end{array}$ & Método a qual se obtém o peso real dos grãos \\
\hline $\begin{array}{l}\text { Limites de } \\
\text { liquidez }\end{array}$ & $\begin{array}{l}\text { (NBR 6459/84) - Determinação do limite de } \\
\text { liquidez. }\end{array}$ & $\begin{array}{l}\text { O limite de liquidez de um solo denomina-se sendo o teor de } \\
\text { umidade acima do qual o solo perde suas características de } \\
\text { plasticidade, sendo assim comportando-se como fluido. }\end{array}$ \\
\hline $\begin{array}{l}\text { Limites de } \\
\text { plasticidad } \\
\text { e }\end{array}$ & $\begin{array}{l}\text { (NBR 7180) - Determinação do limite de } \\
\text { plasticidade. }\end{array}$ & $\begin{array}{l}\text { O limite de plasticidade consiste em representar o teor de umidade } \\
\text { em que o solo a parti do qual passa a se ter características plásticas }\end{array}$ \\
\hline $\begin{array}{l}\text { Permeabili } \\
\text { dade }\end{array}$ & $\begin{array}{l}\text { (NBR 13292) - Determinação do coeficiente } \\
\text { de permeabilidade de solos granulares à } \\
\text { carga constante }\end{array}$ & $\begin{array}{l}\text { Método para a determinação do coeficiente de permeabilidade a } \\
\text { carga constante, com a água percolando através do solo, em regime } \\
\text { de escoamento laminar. }\end{array}$ \\
\hline
\end{tabular}


A determinação dos empuxos atuantes é o passo mais importante na análise de muros de arrimo. Utilizamos a teoria de Coulom nesta determinação, pois ela fornece valores realistas para estes empuxos. Para tanto é necessário identificar as forças presentes no muro que são: empuxo ativo 'Ea', empuxo passivo 'Ep' e o peso próprio da estrutura ' $P$ '. Os valores para os coeficientes de empuxo segundo a teoria de Coulomb são:

$$
\begin{aligned}
& \mathrm{E}_{\mathrm{a}}=\frac{1}{2} \gamma \cdot \mathrm{h}^{2} \cdot \mathrm{K}_{\mathrm{a}} \\
& \mathrm{K}_{\mathrm{a}}=\frac{\operatorname{Sen}^{2}(\alpha+\phi)}{\operatorname{Sen}^{2} \alpha \operatorname{Sen}(\alpha-\delta)\left[1+\sqrt{\frac{\operatorname{Sen}(\phi+\delta) \operatorname{Sen}(\phi-\beta)}{\operatorname{Sen}(\alpha-\delta) \operatorname{Sen}(\alpha+\beta)}}\right]^{2}} \\
& E_{p}=\frac{1}{2} \gamma \cdot h^{2} \cdot K_{p} \\
& \mathrm{~K}_{\mathrm{p}}=\frac{\operatorname{Sen}^{2}(\alpha+\phi)}{\operatorname{Sen}^{2} \alpha \operatorname{Sen}(\alpha-\delta)\left[1-\sqrt{\frac{\operatorname{Sen}(\phi+\delta) \operatorname{Sen}(\phi-\beta)}{\operatorname{Sen}(\alpha-\delta) \operatorname{Sen}(\alpha+\beta)}}\right]^{2}}
\end{aligned}
$$

Sendo:

$E_{a}=$ Empuxo Ativo $(\mathrm{kPa}), \mathrm{Ep}=$ Empuxo Passivo $(\mathrm{kPa}), \gamma=$ Peso Específico $\left(\mathrm{Kn} / \mathrm{m}^{3}\right)$

h: Altura do solo $(\mathrm{m}), \mathrm{Ka}=$ Coeficiente de empuxo ativo, $\mathrm{Kp}=$ Coeficiente de empuxo passivo , $\Phi=$ Ângulo de atrito, c= Coesão, $\alpha=90^{\circ}, b=0^{\circ}, \delta=0^{\circ}$

Obtido o empuxo iniciou-se as verificações de desempenho da estrutura quanto ao deslizamento, tombamento e capacidade de carga. A segurança contra o deslizamento consiste na verificação do equilíbrio das componentes horizontais das forças atuantes, com a aplicação de um fator de segurança adequado:

$$
F S_{\text {DESLIZ }}=\frac{\sum \mathrm{F}_{\mathrm{RES}}}{\sum \mathrm{F}_{\text {SOLIC }}} \geq 1,5
$$

Onde: $\sum \mathrm{F}_{\text {res }}=$ somatório dos esforços resistentes; $\sum \mathrm{F}_{\text {solic }}=$ somatório dos esforços solicitantes; $\mathrm{FS}_{\text {desliz }}=$ fator de segurança contra o deslizamento. A Figura 7 ilustra os esforços atuantes no muro. $O$ fator de segurança contra o deslizamento será:

$$
F S_{\text {DESLIZ }}=\frac{\mathrm{E}_{\mathrm{P}}+\mathrm{S}}{\mathrm{E}_{A}} \geq 1,5
$$

Onde: $\mathrm{Ep}=$ empuxo passivo; $\mathrm{Ea}=$ empuxo ativo; $\mathrm{S}=$ esforço cisalhante na base do muro. $\mathrm{O}$ empuxo passivo, quando considerado, deve ser reduzido por um Fator de segurança entre 2 e 3, uma vez que sua mobilização requer a existência de deslocamentos significativos. Alternativamente, esta componente pode ser simplesmente desprezada.

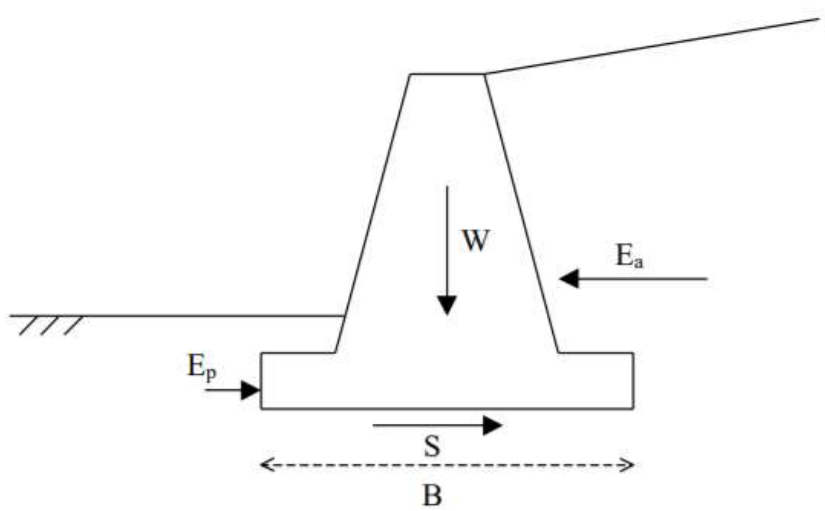

Figura 7: Segurança contra o deslizamento. Fonte: Gerscovich (2008). 
O valor de S é calculado pelo produto da resistência ao cisalhamento na base do muro vezes a largura (Tabela 1).

Tabela 1: Equações para segurança contra o deslizamento.

\begin{tabular}{|c|c|c|}
\hline Tipo de analise & Solo & Equação \\
\hline Longo prazo & Permeabilidade alta & $\mathrm{S}=\mathrm{B} \mathrm{x} \mathrm{c}_{\mathrm{w}}^{\prime}+\left(\frac{\mathrm{W}}{B}-\mathrm{u}\right) \tan \delta$ \\
\hline
\end{tabular}

Notas: $\delta=$ atrito solo-muro, $\mathrm{B}=$ largura da base do muro; $\mathrm{c}_{\mathrm{w}}^{\prime}=$ adesão solo-muro; $\mathrm{W}=$ somatório das forças verticais; $\mathrm{u}=$ poropressão

Fonte: Gerscovich (2008).

Para que o muro não tombe em torno da extremidade externa (ponto $\mathrm{A}$ da Figura 8), o momento resistente deve ser maior do que o momento solicitante. 0 momento resistente $\left(\mathrm{M}_{\text {res }}\right)$ corresponde ao momento gerado pelo peso do muro. O momento solicitante $\left(M_{\text {solic }}\right)$ é definido como o momento do empuxo total atuante em relação ao ponto $\mathrm{A}$. O coeficiente de segurança contra o tombamento é definido como a razão:

$$
\begin{aligned}
F S_{\text {TOMB }} & =\frac{\mathrm{M}_{\mathrm{RES}}}{\mathrm{M}_{\text {SOLIC }}} \geq 1,5 \\
F S_{\text {TOMB }} & =\frac{\mathrm{W} \cdot \mathrm{x}_{1}+\mathrm{E}_{\mathrm{AV}} \cdot \mathrm{X}_{2}}{E_{A H} \cdot y_{1}} \geq 1,5
\end{aligned}
$$

A capacidade de carga consiste na verificação da segurança contra a ruptura e deformações excessivas do terreno de fundação. A análise geralmente considera o muro rígido e a distribuição de tensões linear ao longo da base (GERSCOVICH, 2008). Além das verificações feitas anteriormente, deve-se verificar a possível ruptura global do maciço. Este tipo de ruptura ocorre normalmente quando existem camadas ou zoneamentos de solos menos resistentes abaixo da fundação ou do muro de arrimo. Para a análise de estabilidade global foi adotada o método de Bishop. A forma deste deslizamento é bem similar à forma de ruptura que ocorre em taludes, logo são utilizados os métodos de análise de estabilidade de taludes para verificar-se a ruptura global de um muro de arrimo.

O método empregado foi o de Bishop utilizando superfícies de ruptura cilíndrica. A grande vantagem do método de Bishop é poder considerar diferentes tipos de situações para o mesmo solo, como: camadas de solos diferentes, pressões neutras, sobrecargas, lençol freático entre outros. Além do mais, a superfície cilíndrica considerada para cálculo aproxima-se mais das rupturas observadas em campo. É necessário pesquisar várias superfícies de rupturas até se encontrar a superfície mais crítica que é aquela que possui o menor valor de coeficiente de segurança (MACCAFERRI, 2010).

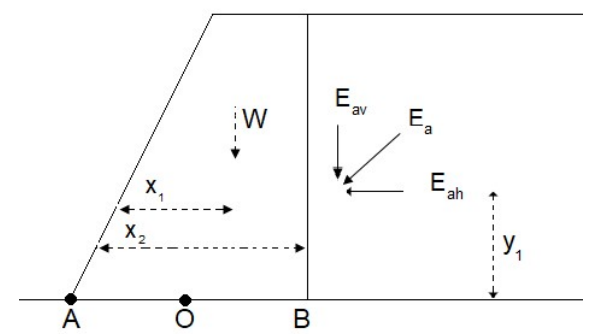

Figura 8: Segurança contra o tombamento. Fonte: Gerscovich (2008). 


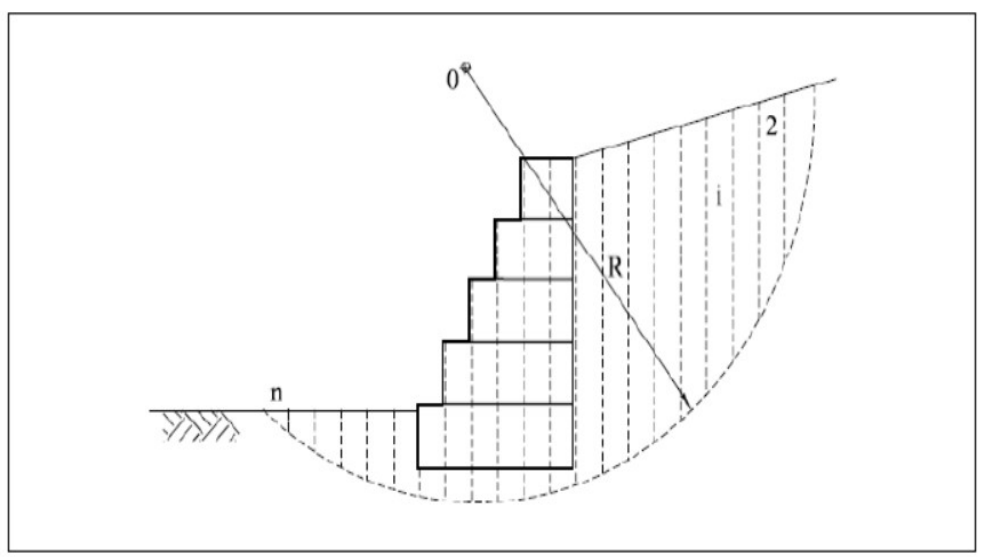

Figura 9: Método de Bishop (superfície de ruptura cilíndrica). Fonte: Maccaferri (2010).

\section{RESULTADOS E DISCUÇõES}

Primeiramente foi definida uma seção típica para a análise e proposta de solução do problema, conforme a Figura 6. Após a definição do problema e a proposta de solução iniciou-se a busca por a determinação dos parâmetros a serem adotados. Para a camada 1 composta por solo de aterro e a camada 3 composta por solo argiloso arenosos, os parâmetros foram adotados conforme a prática de projeto da região, visto que estes materiais são extensamente estudados no laboratório de Solos do ITPAC Porto. Já a camada 2, não era um solo esperado, com características bem distintas, para este solo foram coletadas amostras deformadas e indeformadas. Os resultados dos ensaios estão dispostos no quadro 2.

Quadro 2: Resultados dos ensaios.

\begin{tabular}{|l|l|}
\hline Ensaio & Resultado \\
\hline Granulometria & Areia fina siltosa \\
\hline Massa específica dos sólidos & $\rho=2,801 \mathrm{~g} / \mathrm{cm}^{3}$ \\
\hline Limites de liquidez & Não Liquido \\
\hline Limites de plasticidade & Não Plástico \\
\hline Permeabilidade & $1,8 \mathrm{E} \mathrm{cm} / \mathrm{s}$ \\
\hline
\end{tabular}

A Tabela 2 mostra os parâmetros adotados neste trabalho que compuseram a definição da problemática e análise da estabilidade da estrutura proposta. Com todas estas informações foi possível inserir os dados básicos para a resolução do problema utilizando o programa Geo5. Os resultados das análises de tombamento e de deslizamento são satisfatórios com um fator de segurança de 3,82 e 1,66 respectivamente. Conforme a norma regente NBR 11682/1991 as análises estão adequadas. A Tabela 3 e 4 apresenta os resultados obtidos na verificação do tombamento e deslizamento.

Tabela 2: Dimensões das camadas de solo.

\begin{tabular}{|l|l|l|l|}
\hline Solo & Peso especifico $\left(\mathrm{kN} / \mathrm{m}^{3}\right)$ & Coesão $(\mathrm{kPa})$ & Ângulo de atrito () \\
\hline 1 & 18,00 & 5,00 & 25 \\
\hline 2 & 17,00 & 0,00 & 30 \\
\hline 3 & 20,00 & 0,00 & 35 \\
\hline
\end{tabular}

Tabela 3: Verificação para estabilidade de Tombamento.

\begin{tabular}{|l|l|}
\hline Verificação para estabilidade de tombamento \\
\hline Resistência de momento & $\mathrm{M}_{\text {res }}=85,00 \mathrm{kN} / \mathrm{m}$ \\
\hline Momento de tombamento & $\mathrm{M}_{\text {ovr }}=22,25 \mathrm{kN} / \mathrm{m}$ \\
\hline Fator de segurança & $3,82>1,50$ \\
\hline Parede para tombamento É SATISFATÓRIA & \\
\hline
\end{tabular}


Tabela 4: Verificação para o Deslizamento.

\begin{tabular}{|l|l|}
\hline Verificação de deslizamento \\
\hline Reação horizontal & $\mathrm{H}_{\text {res }}=39,26 \mathrm{kN} / \mathrm{m}$ \\
\hline Força horizontal ativa & $\mathrm{H}_{\mathrm{act}}=23,63 \mathrm{kN} / \mathrm{m}$ \\
\hline Fator de segurança & $1,66>1,50$ \\
\hline Parede para deslizamento É SATISFATÓRIA & \\
\hline
\end{tabular}

$\mathrm{Na}$ análise de capacidade de carga verificou-se fator de segurança de 30,84. A Tabela 6 apresenta os resultados obtidos na verificação para a capacidade de carga. Para a análise de estabilidade global foi adotado o método e Bishop, verificou-se um fator de segurança de 1,52. A Tabela 7 apresenta os resultados obtidos na verificação da estabilidade do talude. As Figuras 10, 11 e 12, na sequência, apresentam os resultados obtidos através do programa GEO5 às quatro análises obrigatórias de deslizamento, tombamento, capacidade de carga e análise de estabilidade global do talude.

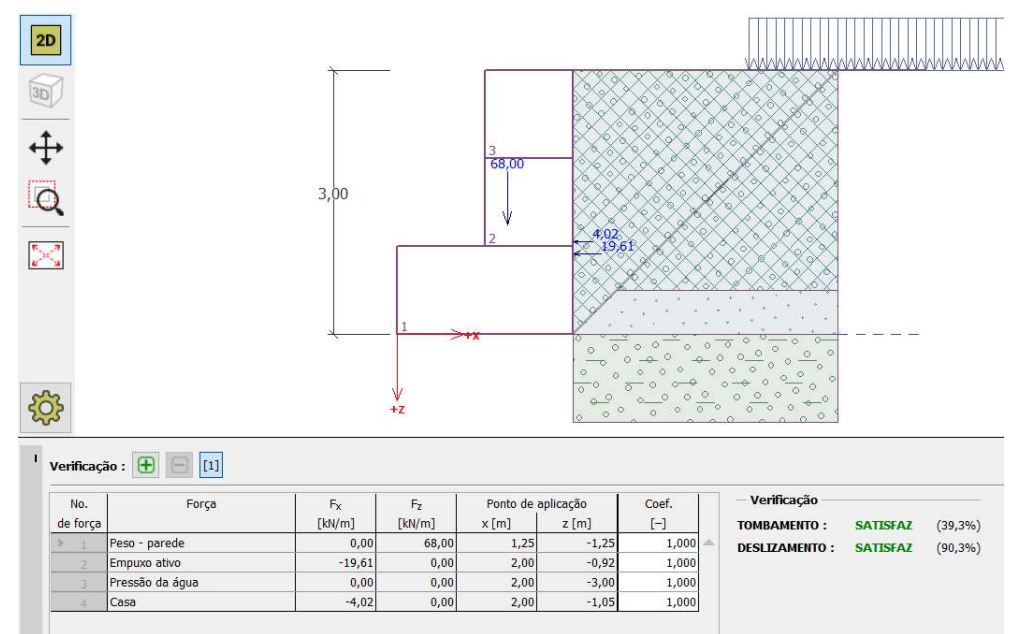

Figura 10: Verificação para o tombamento e deslizamento.

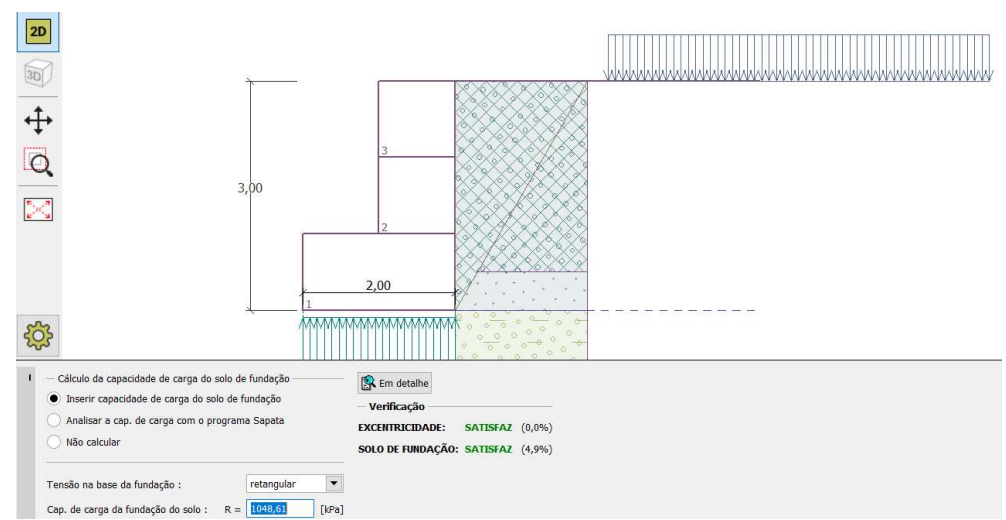

Figura 11: Verificação para a capacidade de carga.

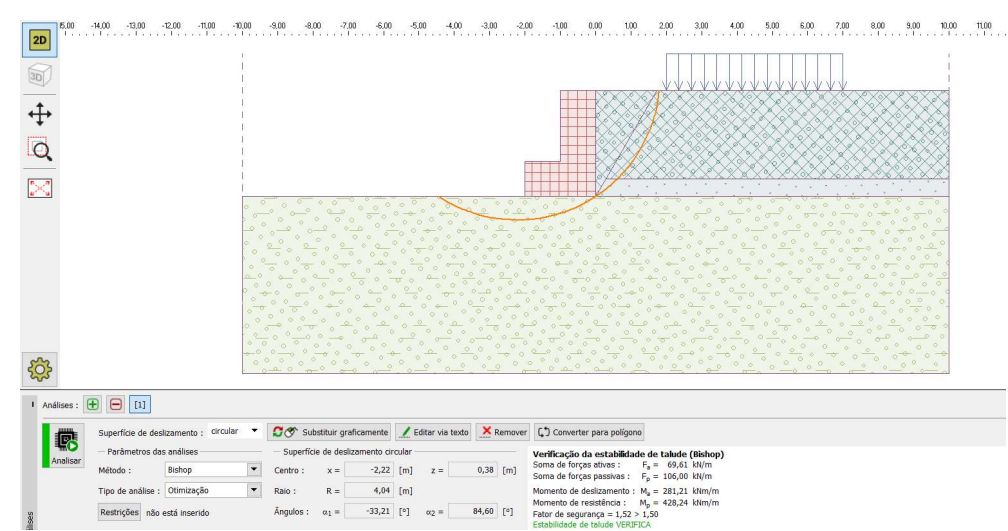

Figura 12: Verificação para estabilidade do talude. 


\section{CONCLUSÕES}

Conforme os resultados obtidos e discutidos, anteriormente, verificam-se que a estrutura proposta atende aos quesitos de segurança previstos pela NBR 11682/1991, seja para o tombamento, deslizamento, capacidade de carga e ruptura global. Trabalhos futuros serão realizados com o intuito de verificar e propor outras soluções técnicas para este problema, e por fim avaliar a qual será economicamente mais viável e apresentar ao poder público para a solução definitiva do problema recorrente de erosão devido à falha na drenagem urbana.

\section{REFERÊNCIAS}

BARBOSA, C. A. F.. Soluções para Estabilização de Taludes Sujeitos a Erosão Superficial. Dissertação (Mestrado em Engenharia Civil) - Universidade de Aveiro, Aveiro, 2008.

ABNT. Associação Brasileira de Normas Técnicas. NBR 11682. Estabilidade de taludes. Rio de Janeiro: ABNT, 1991.

ABNT. Associação Brasileira de Normas Técnicas. NBR 13292. Solo: Determinação do coeficiente de permeabilidade de solos granulares a carga constante. Rio de Janeiro: ABNT, 1995.

ABNT. Associação Brasileira de Normas Técnicas. NBR 6457. Amostras de Solo: Preparação para ensaios de compactação e ensaios de caracterização. Rio de Janeiro: ABNT, 1986.

ABNT. Associação Brasileira de Normas Técnicas. NBR 6459. Solo: Determinação do Limite de Liquidez. Rio de Janeiro: ABNT, 2016.

ABNT. Associação Brasileira de Normas Técnicas. NBR 6508. Solo: Grãos de solos que passam na peneira de $4,8 \mathrm{~mm}-$ Determinação da massa específica. Rio de Janeiro: ABNT, 1984.

ABNT. Associação Brasileira de Normas Técnicas. NBR 7180. Solo: Determinação do Limite de Plasticidade. Rio de Janeiro: ABNT, 1984.

ABNT. Associação Brasileira de Normas Técnicas. NBR 7181. Solo: Análise Granulométrica. Rio de Janeiro: ABNT, 1984.
CAMAPUM, J. C.; SALES, M. M.. Processos Erosivos no Centro-Oeste Brasileiro. Brasília: FINATEC, 2006.

CARMO, E. S.. Análise da Estabilidade de um Talude de Corte da BR-110: Estudo de Caso. Monografia (Graduação) Universidade Federal de Feira de Santana, Feira de Santana, 2009.

DOMINGUES, E. N.; ROSSI, M.; MATTOS, I. F. A.; ABE, K.; KITADA, M.. Tipologia e distribuição dos processos erosivos na microbacia do ribeirão água da cachoeira, em Paraguaçu paulista, SP. Revista Brasileira de Ciências do Solo, v.22, n.1, p.141-149, 1998

GERSCOVICH, D. M. S.. Estruturas de Contenção: Muros de Arrimo. 2008.

GUERRA, A. J. T.. Erosão e conservação dos solos: conceitos, temas e aplicações. 2 ed. Rio de Janeiro: Bertrand Brasil, 2005.

MACCAFERRI. Gabiões e outras soluções em malha hexagonal de dupla torção: necessidades e soluções. Publicação Técnica. São Paulo, 2010.

MACCAFERRI. Obras de contenção: manual técnico. Publicação Técnica. São Paulo, 2009.

PEREIRA, A. R.. Nova Tecnologia no Controle de Erosões e Revegetação de Áreas Degradadas. In: SIMPÓSIO BRASILEIRO DE MINÉRIO DE FERRO, 1. Anais. Ouro Preto: Associação Brasileira de Metalurgia e Materiais, 1996.

A CBPC - Companhia Brasileira de Produção Científica (CNPJ: 11.221.422/0001-03) detém os direitos materiais desta publicação. Os direitos referem-se à publicação do trabalho em qualquer parte do mundo, incluindo os direitos às renovações, expansões e disseminações da contribuição, bem como outros direitos subsidiários. Todos os trabalhos publicados eletronicamente poderão posteriormente ser publicados em coletâneas impressas sob coordenação da Sustenere Publishing, da Companhia Brasileira de Produção Científica e seus parceiros autorizados. Os (as) autores (as) preservam os direitos autorais, mas não têm permissão para a publicação da contribuição em outro meio, impresso ou digital, em português ou em tradução. 